\title{
Influence of the Environmental Conditions, the Variety, and Different Cultural Practices on the Phenology of Peach in the Central Area of Santa Fe (Argentina)
}

\author{
Norberto Gariglio, Marcela Weber, \\ Damián Castro and Norma Micheloud \\ Facultad de Ciencias Agrarias, Universidad Nacional del Litoral, \\ Argentina
}

\section{Introduction}

Phenology is the study of the rhythm of repetitive biological events, the biotic and abiotic causes of these events, and the relationship between phenophases (i.e. periods during which specific phenological events occur) for individual or different species (Lieth, 1974). The knowledge of the phenological patterns of fruit tree crops is essential to estimate their behavior in a new growing area by extrapolation of experimental results from one region to another, or to predict changes in the tree phenology in a given area caused by the variation of the environmental factors between years (Broadhead et al., 2003). Thus, phenological studies can provide criteria for selection of suitable genotypes, helping to improve fruit yield and quality, and reduce environmental risk (Petri et al., 2008).

The time of flowering strongly influences the reproductive traits of animal-pollinated plants (Kudo, 2006), being one of the most important phenological events of the temperate fruit tree crops. The occurrence of late frosts during blooming or at fruit set can severely affect the annual fruit tree production, mainly in early flowering plants such as stone fruits. Harvesting time also has a great agronomic interest in temperate fruit trees, since each variety of peach, plum and nectarine has its own specific harvest time which lasts for about 10 days. Furthermore, these fruits have a short shelf life (Gorny et al., 1999); therefore, cultivation of a large number of crop varieties with a harvesting period in succession in time is required so that a farm or an entire production area can achieve a wide harvest period and a long presence in the regional market.

Fruit tree production in Argentina is over 7.5 million T, mainly including citrus $(32.5 \%)$, grape $(31.5 \%)$, pomes fruits $(26.5 \%)$, stone fruits $(5.3 \%)$, tropical fruits $(3 \%)$, and other minor fruits $(1.3 \%)$ such as walnuts, cherries and figs (CFI, 2011). The Santa Fe province contributes a small proportion of the whole fruit tree production of Argentina (INDEC, 2002), but there is an important encouragement for the expansion of fruit tree crops, due to the propitious ecological conditions, the abundant availability of high quality water, and the possibility of obtaining early fruit production (Gariglio et al., 2009). Nearly 50 new smallscale enterprises over 50 hectares of different crops such as low chilling peach and apple, 
raspberry, fig and citrus appeared in the last four years in the central area of the province, allowing the diversification of the production system characterized by the cultivation of annual horticultural crops.

One of the most widespread fruit tree crops in Argentina is peach (Prunus persica L. Batsch), which is grown on 29,660 hectares mainly located in the Mendoza and Buenos Aires provinces (INDEC, 2002). Both area of production are characterized by the use of medium and high chilling varieties (Carrá de Toloza, 2001; Valentini, 2002). In contrast, in the centraleast area of Santa Fe, early maturing peach varieties are mainly used (Gariglio et al., 2009) because their low chilling requirements are compatible with the accumulation of cold in the region ( $\approx 300$ chilling hours), which is lower than half in comparison with the traditional peach production areas of Argentina (Gariglio et al., 2006a).

The quantity of chilling hours accumulated in a certain area is a very important ecological requirement for the adaptation of temperate fruit trees (Erez et al., 1998; Faust, 1989; Lang, 1996; Squire, 1990) due to the influence of chilling on the release of dormancy (Dennis, 2002; Faust et al., 1997). Currently there is no valid method for the quantification of chilling accumulation in the region. Consequently, it is important to test the agronomic behavior of a wide range of varieties, mainly those with low chilling requirements, which are not widely grown and known in Argentina (Alayón Luaces et al., 2004). The introduction and evaluation of low chilling fruit trees in Santa Fe occurred from 1996, and now at least 10 varieties have been recommended for cultivation in view of their adequate phenological and reproductive traits (Gariglio et al., 1999, 2006b, 2009; Ortiz de Zárate et al., 2007). However, these studies are still continuing due to the rapid varietal replacement and the interaction between environment and genotype, which requires many years of research.

The phenology and the agronomic performance of peach trees may be greatly affected by some cultural practices. Autumn defoliation, for example, can modify the time of spring bloom. However, the results have been contradictory; in some cases it was observed that autumn defoliation delayed spring bloom of peach trees (Couvillon \& Lloyd, 1978), whereas in others it was reported that warm field temperatures delayed defoliation extending the rest period (Walser et al., 1981). Moreover, removal of leaves of low chilling apple at the onset of winter released dormancy and advanced flowering (Mohamed, 2008).

The study of dormancy is difficult under field conditions where solar radiation, diurnal fluctuations in temperature and other factors cannot be controlled (Dennis, 2003). Consequently, it is considered that experiments using isolated buds as one-node cuttings (Balandier et al., 1993) or excised shoots (Dennis, 2003) are appropriate methods for studying dormancy. This was the methodology adopted in our experiments.

Pruning also greatly affects the performance of the fruit trees. The traditional pruning of peach trees is done during winter (Marini, 2003), and is a time-consuming cultural practice that demands highly skilled labor. In addition, low chilling peach trees in our region have a short period of winter rest which limits the time for winter pruning to only 30-40 days. As a consequence, this agronomical practice is difficult to implement and usually fails to be completed. However, low chilling peach has a long growing season after the harvest period. Thus, pruning the fruit-bearing shoots after harvesting is an alternative cultural practice that may be used to extend the time for pruning and to encourage the growth of the new desirable shoots (Weber et al., 2011). Summer pruning is generally used as a complementary method to winter pruning, but it has not been sufficiently evaluated as an alternative to 
traditional winter pruning for reproductive shoots renovation. Thus, the effect of summer pruning on the phenology and on a range of vegetative and reproductive parameters of peach trees may be evaluated before recommending this cultural practice.

The aim of this work was to study the phenological behavior and the reproductive traits of different peach and nectarine varieties in the central area of Santa Fe, Argentina. Extreme changes in the phenology of peach varieties in a nine-year period were analyzed taking into account temperature, chilling requirements of the varieties, and the influence of cultural practices such as artificial defoliation and summer pruning.

\section{Material and methods}

This research was carried out in Esperanza city (31 26' S; 60 56' W.; $40 \mathrm{~m}$ above sea level), in Santa Fe, Argentina. Table 1 summarizes temperature and rainfall conditions in the study area.

\begin{tabular}{lccc}
\hline & Average & Maximum & Minimum \\
\hline Annual temperature $\left({ }^{\circ} \mathrm{C}\right)$ & 18.95 & 19.55 & 18.08 \\
Maximum annual temperature $\left({ }^{\circ} \mathrm{C}\right)$ & 25.61 & 26.85 & 24.55 \\
Minimum annual temperature $\left({ }^{\circ} \mathrm{C}\right)$ & 13.24 & 13.63 & 12.67 \\
Warmest month temperature $(\mathrm{January})$ & 25.94 & 27.20 & 25.10 \\
Coldest month temperature $(\mathrm{July})$ & 12.07 & 15.50 & 9.00 \\
Chilling accumulation $(\mathrm{CH} \mathrm{H})$ & 301 & 493 & 183 \\
Annual rainfall & 1004 & 1426 & 571 \\
\hline
\end{tabular}

Table 1. Main temperature and rainfall parameters in the central-east area of Santa Fe, Argentina. Data are the means of nine years (2002-2010).

Four-year-old peach trees (Prunus persica L. Batsch) were used, planted $5 \times 3 \mathrm{~m}$ apart in a silty-loamy soil and grafted onto 'Cuaresmillo' seedling rootstock, with complementary drip irrigation and trained to the standard open vase system. Fifteen peach and five nectarine (n) cultivars with different chilling requirements were evaluated: 'Spring Lady', (650 chilling hour $(\mathrm{CH})$ requirement), 'Maycrest' $(600 \mathrm{CH})$, 'June gold' $(520 \mathrm{CH})$, 'Flavorcrest' (509 CH), 'Flordaking' (450 CH), 'Hermosillo' (350 CH), 'Don Agustín' (Fla. 8112; $300 \mathrm{CH})$, 'San Pedro 1633' (297 CH), 'Early grande' (260 CH), 'Tropic snow' (250 CH), 'Flordastar' (250 CH), 'Flordaprince' (150 CH) (Valentini, 2002), 'Fla. 91-8c' (100 CH, according to its behavior in Santa Fe, Argentina), 'Fla 1-8', 'Fla 1-8 bis', 'Lara' (n) (350 CH), 'Carolina' (n) (325 CH) (INIA Salto Grande, 2003), 'Nectarina 22', 'Nectarina 24', and 'Nectarina 29'. Where cultivars' chilling requirements are not presented, it is because they are unknown, but according to their vegetative and reproductive traits, using the methodology of excised shoots exposed to artificial chilling (Dennis, 2003), and observations of their behavior in the experimental orchards in the central area of Santa Fe (unpublished data), their need is lower than $350 \mathrm{CH}$.

\subsection{Phenology and reproductive traits of peach and nectarine}

Trees of each variety were chosen by their uniformity in size and vigor. During the winter, 10 homogeneous current season shoots per plant were randomly selected at $1.8 \mathrm{~m}$ above the ground level and their length was measured. The phenological phases of leafing, beginning of flowering, full flowering, and fruit set, were observed weekly from the end of the winter 
rest to the end of harvest time in these twigs by using the Biologische Bundesanstalt, Bundessortenamt and Chemical industry (BBCH) scale for stone fruit (Meier et al., 1994). Furthermore, the number of new vegetative shoots, flowers and fruits were measured weekly on the one-year-old selected shoots from the release of dormancy to the stage of pit hardening. Data were expressed as the mean number of flowers per meter of shoot length, percentage of vegetative bud break, and percentage of fruit set. The percentage of fruit set was calculated as the ratio between the number of fruit at pit hardening and the maximum number of flowers measured at full bloom in each selected twig. The experiment was conducted over a nine-year period (2002-2010), with the exception of 'Fla 1-8', 'Fla 1-8 bis', 'Nectarina 22', 'Nectarina 24', and 'Nectarina 29', in which the study was conducted over three years (2008-2010).

A randomized complete-block design with one-tree plots and eight replications per cultivar was used. Analysis of regression and variance was performed on the data, and means were compared by Tukey's test $(p \leq 0.05)$. Extreme date of the occurrence of each phenological stage in the nine-year period were recorded and expressed in days. Extreme variation of the medium month temperature was also registered and expressed as a percentage of the medium value. The relationships between the variability of the phenological stage with the chilling requirement of the variety, and with climatic data were performed using the Infostat software.

\subsection{Autumn defoliation and peach phenology}

This experiment was conducted over three consecutive years (2005-2007) using trees of the cv. 'Flordaking'. Two treatments were performed; at the beginning of leaf fall plants were manually defoliated (D) whereas another group of plants remains as control (C) in which the physiological process of autumn leaf fall occurred naturally. Ten twigs per tree were randomly and periodically collected from both treatments $(20,50,65$, and 90 days after leaf fall) from leaf fall to the end of July, to measure the evolution of dormancy during the rest period. Twigs were cut into segments $15 \mathrm{~cm}$ long obtaining 80 stem cuttings for each treatment. Only one node with three axillary buds (two floral buds and one central leaf bud) per stem cutting was kept, removing the remaining buds.

Excised shoots were placed with their basal tip in water and forced in a phytotron with an 8-h photoperiod $\left(22.5 \mathrm{mmol} \mathrm{m}^{-2} \mathrm{~s}^{-1}\right)$ (Citadin et al., 2001), at $20.0 \pm 1.0^{\circ} \mathrm{C}$. The basal ends of the shoots were cut weekly and water was replaced daily (Balandier et al., 1993; Citadin et al., 1998). Floral and leaf budbreak were observed three times a week. The number of buds that reached the balloon or green tip stage was recorded (Citadin et al., 2001). Results were expressed as the percentage of excised shoots that reached floral and vegetative budbreak, and as the mean time of budbreak (MTB). MTB was expressed in days (arithmetic mean of each eight groups of 10 excised shoots) (Balandier et al., 1993). This trial was conducted in a complete randomized design with eight replicates of 10 cuttings per treatment. In the field, phenological phases and reproductive traits of peach trees were observed on selected shoots as was described previously (see item 2.1). A randomized complete-block design with onetree plots of eight replications each was used.

\subsection{Summer pruning and peach phenology}

Two experiments were conducted over seven consecutive years (2002-2008), using six-yearold peach trees [Prunus persica (L.) Batsch], cvs. 'Flordaking' and 'Early grande' grafted onto 'Cuaresmillo' seedling rootstocks. 
In the first experiment (2002-2004), representative trees of the cv. 'Flordaking' selected for their uniformity in size and trunk girths received different treatments after harvesting, during the first week of November. One group of plants remained unpruned (NP) as control trees, whereas a second group of plants was pruned each year $(\mathrm{P})$. Summer pruning consisted of heading back the recently harvested bearing shoots to basal current season shoots which were at least $10 \mathrm{~cm}$ long; bearing shoots were thinned out when a new current season shoot (10 cm long) protruded directly from the branch framework. In order to avoid sunburn, care was taken not to prune branches that protected the scaffold from direct sunlight. In both treatments, vigorous watersprouts were removed after harvesting. NP trees received traditional dormant pruning 15-25 days before the beginning of their bloom; in $\mathrm{P}$ trees, a light pruning was also performed during the dormant period to remove branches that were previously left to avoid sunburn of the tree scaffold.

In the second experiment, using the cv. 'Early grande', pruning was performed at different times from harvest to 15-20 days before the next flowering. Six times of pruning were evaluated: November, December, February, March, April, and June. The combination of summer pruning with traditional winter pruning (WP) was also evaluated, being performed on 11 treatments: (Nov-P, Nov-P+WP, Dec-P, Dec-P+WP, Feb-P, Feb-P+WP, Mar-P, Mar$\mathrm{P}+\mathrm{WP}, \mathrm{Apr}-\mathrm{P}, \mathrm{Apr}-\mathrm{P}+\mathrm{WP}$ and Jun-P). The last treatment, in which pruning was performed 15-25 days before the beginning of blooming, was considered as control treatment. In trees that received summer and winter pruning, the last were performed to remove branches that were previously left to avoid sunburn of the tree scaffold and to adjust the number of bearing shoots.

In both experiments, phenological phases and reproductive traits of the treatments were evaluated on selected shoots as was mentioned in section 2.1. Moreover, the number and distribution of fruits per plant were evaluated at harvest taking into account their distribution in three levels of plant height; L1: lower, up to $1.5 \mathrm{~m}$ height; L2: intermediate, from 1.5 to $2.5 \mathrm{~m}$ height; and L3: upper, from $2.5 \mathrm{~m}$ and higher.

A randomized complete block design with a single tree plot of five replications was used. The data was tested for normal distribution and variance homogeneity and means were compared via an LSD test using the software Statgraphics plus for Windows 3.1 (Statistical Graphics Corp). A 5\% probability level was used to indicate significant differences between treatments.

\section{Result and discussion}

\subsection{Field behavior of peach and nectarine}

\subsubsection{Time of occurrence of the different phenological stages}

The most precocious peach variety began to sprout the first week of July ('Fla. 91-8c'), but $80 \%$ of the low chilling cultivars sprouted during 10 days from July $11^{\text {th }}$. High chilling requirement genotypes $(>500 \mathrm{CH})$ showed sprouting during the second and third weeks of September, two months later than the low chilling group. With the exception of 'Maycrest' and 'Spring Lady', all cultivars reached over $60 \%$ of budbreak, despite its chilling requirement. These data did not show significant changes from data reported previously for a minor number of varieties and for a shorter period of analysis (Gariglio et al., 2009). 
Full bloom occurred from the middle of July to the first week of August for the low chilling varieties; 'Carolina', 'Lara', 'Flordaprince', and 'Flordaking' being the later cultivars of this group (Fig. 1). On the other hand, full blooming was observed from September $10^{\text {th }}$ to $20^{\text {th }}$ for high chilling varieties. Most low chilling cultivars reached fruit set from August $10^{\text {th }}$ to $23^{\text {rd }}$, whereas those varieties with higher chilling requirements reached fruit set from the end of September, around two months later than the most precocious genotypes (Fig. 1).

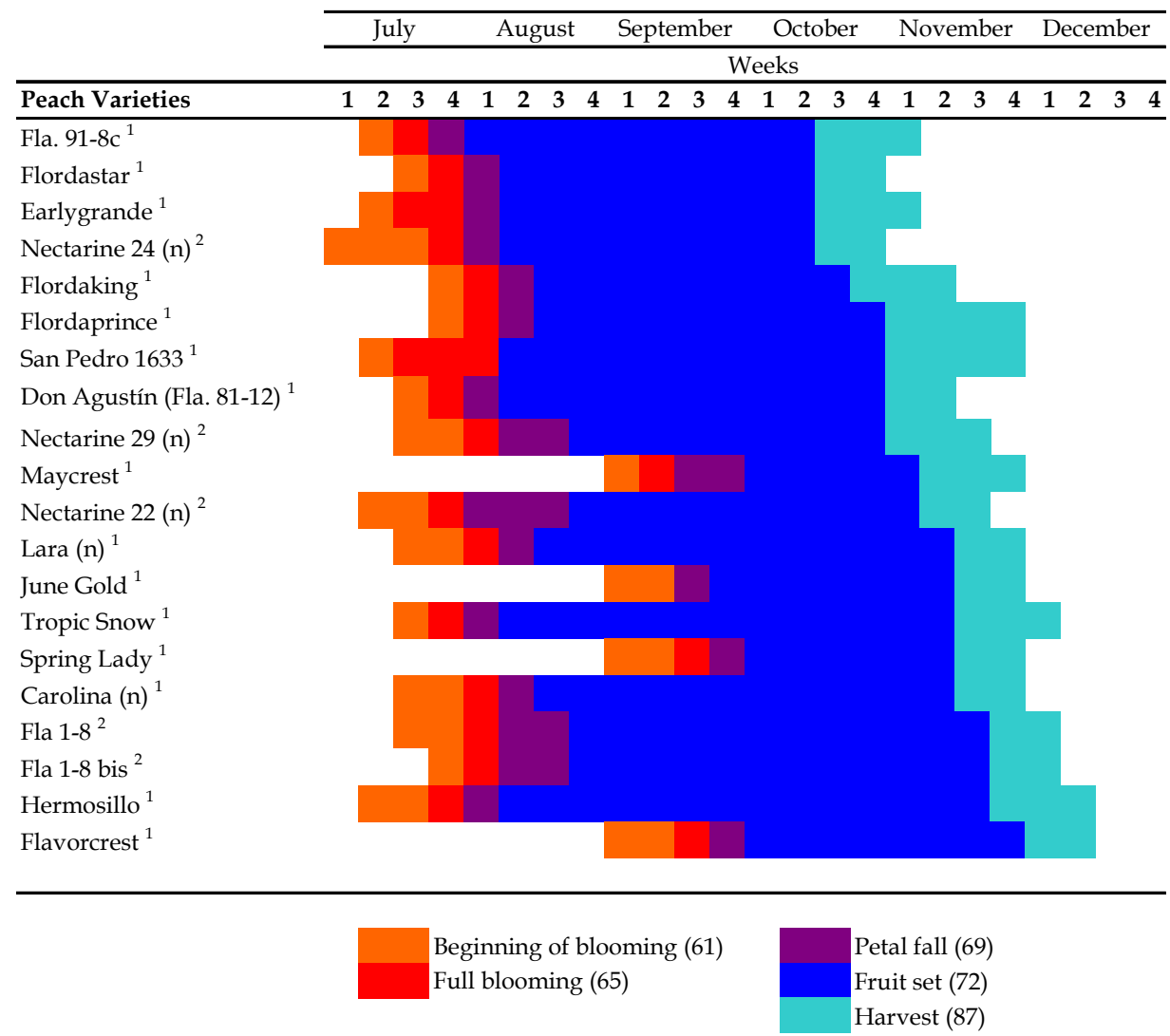

Fig. 1. Main phenological stages for different peach and nectarine (n) cultivars grown in the central-east area of Santa Fe, Argentina. Data are the means of nine-year (2002-2010) (1) or three-year (2008-2010) (2) periods. Numbers in the color legend indicate the phenological stages according to the BBCH scale (Meier et al., 1994).

Harvesting began on October 20th with the cv. 'Flordastar' (Fig. 1), which was around 10 days before the harvesting date of the most important peach production areas of the central region of Argentina (Valentini \& Arroyo, 2000), and finished in the middle of December with the cv. 'Flavorcrest'. The period of harvesting was reduced in 10 days when only low chilling varieties were taken into account, with 'Hermosillo' as the latest harvest variety. 
The harvest showed continuity but the incorporation of new low chilling varieties should be evaluated to prolong the harvesting period. The use of varieties more precocious than 'Flordastar' does not seem to be appropriate because of the risk of late frost occurrence and the difficulty in obtaining a proper fruit size. However, it is possible to extend the whole harvest period, and improve fruit size and quality, with the use of varieties with a later harvest period than 'Hermosillo'. In this way, new low chilling varieties recently incorporated in our experimental orchard are being tested with promising results; therefore, in the future, the harvest period would be extended, reaching nearly three months of duration.

\subsubsection{Influence of the chilling requirements of the variety and the climate on the tree phenology}

The extreme variation in the occurrence of the phenological stages of 15 varieties with different chilling requirements during nine years of study showed that the phenological variability diminished with the advance of the growing cycle (Fig. 2). The extreme variation at the beginning of flowering was nearly 35 days, whereas it reached 21 days at fruit set and only 11 days at harvest (Fig. 2). However, it was observed that the variability at the beginning of blooming reached 55 days for the cv. 'Flordastar', and 48 and 49 days for the cvs. 'Tropic snow' and 'Hermosillo', respectively. On the other hand, the extreme variation at this stage reached only 18 days in 'June gold' and 23 days in 'Maycrest', indicating a reduction in the phenological variability with the increase of the chilling requirement of the variety (Table 2). The model that expresses the relationship between the chilling requirement $(x)$ and the extreme variation (in days) of each variety at a given phenological stage $(y)$ was significant $(P$ $<0.05$ ) from the beginning of flowering to the beginning of fruit set, despite the medium value reached by the coefficient of regression. In contrast, the variation of the phenological stages between extreme years did not show any relationship with the chilling requirement of the variety from the stages of fruit set to harvesting (Table 2).

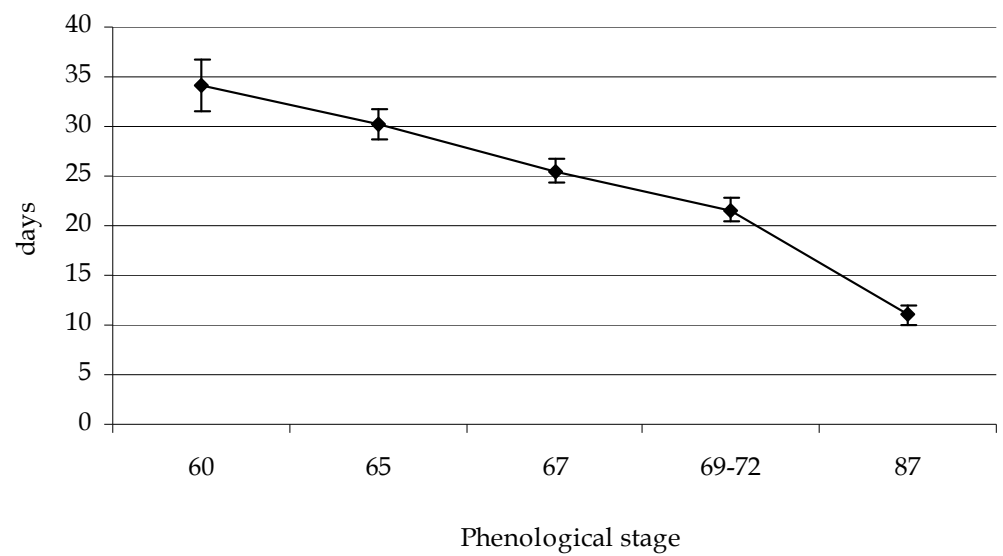

Fig. 2. Maximum variation (in days) in the occurrence of different phenological stages of peach and nectarine trees in the central-east area of Santa Fe, Argentina. Data are the means of 15 varieties with different chilling requirements $(150-650 \mathrm{CH})$ during nine years. Phenological stages according to the BBCH scale (Meiers et al., 1994): $60=$ beginning of flowering; 65 = full flowering; 67 = beginning of fruit set; $69-72$ = fruit set; 87 = harvesting. 


\begin{tabular}{lccc}
\hline Phenological stage & Model & $\mathrm{r}^{2}$ & $\mathrm{p}$-value \\
\hline Beginning of flowering & $\mathrm{y}=-0,0344 \mathrm{x}+46,65$ & 0.23 & 0.046 \\
Full flowering & $\mathrm{y}=-0,0280 \mathrm{x}+40,39$ & 0.32 & 0.045 \\
Beginning of fruit set & $\mathrm{y}=-0,0239 \mathrm{x}+34,21$ & 0.38 & 0.025 \\
Fruit set & $\mathrm{y}=-0,0023 \mathrm{x}+22,43$ & 0.003 & 0.850 \\
Harvesting & $\mathrm{y}=0,0078 \mathrm{x}+8,184$ & 0.071 & 0.380 \\
\hline
\end{tabular}

Table 2. Equation, coefficient of regression $\left(\mathrm{r}^{2}\right)$ and p-value of the model that represents the relationships between the extreme variations ( $y$, in days) of different phenological stage occurrence during the nine-year period (2002-2010) with the chilling requirement of the variety $(x)$.

The higher phenological variability observed in low chilling peach trees can be explained by taking into account the physiology of dormancy of peach and the temperature conditions in the central area of Santa Fe. The depth of dormancy (measured by the MTB value) declines with the accumulation of chilling in all peach varieties (Balandier et al., 1993; Citadin et al., 2001; Gariglio et al., 2006b). This means that the need of heat, expressed as growing degree day (GDD) accumulation over $7^{\circ} \mathrm{C}$ to reach flowering decreases with chilling (Balandier, 1993; Citadin et al., 2001). However, low chilling peach trees have a very low depth of dormancy that allows them to reach more than $50 \%$ of floral budbreak in less than 30 days (MTB value) when they were forced at $25^{\circ} \mathrm{C}$ and without any need of chilling (Gariglio et al., $2006 \mathrm{~b})$. On the other hand, peach varieties with higher chilling requirements $(>500 \mathrm{CH})$ were unable to reach budbreak when they were forced at $25^{\circ} \mathrm{C}$ due to their major depth of dormancy (major MTB value), and they need a certain accumulation of chilling to diminish their heat requirement for blooming. However, during May and June, only 120 chilling hours were accumulated as an average of the last nine years in the central area of Santa Fe (Gariglio et al., 2006a), which is insufficient to cause an important modification of the depth of dormancy of these varieties.

Furthermore, the major variability of the average medium temperature and that of the monthly heat accumulation observed in the central area of Santa Fe occurs from May to August, being highest during July (Fig. 3), coinciding with the period of dormancy and flowering of low chilling peach. As a consequence, the variability of the temperatures between years that occurs during the first period of dormancy, and that modifies chilling and GDD accumulation, mainly affects the phenology of the next growing cycle of low chilling varieties, explaining the major variation of the phenology of these groups in comparison with that of high chilling varieties. This last group reaches blooming when the climatic variability decline and the GDD accumulation increases nearly $80 \%$ in comparison with that of the time of flowering of low chilling peach. Furthermore, the high GDD accumulation allows compensation for the differences in the phenology between years of high chilling varieties in a minor lapse of days, reducing its variability. In the same way, high GDD accumulation and the lower climatic variability can explain why the difference in the occurrence of the phenological events between years diminished with the advance of the growing cycle (Fig. 2).

\subsubsection{Reproductive traits of peach and nectarine}

Most of the studied varieties showed a flower density (FD) between 20 and 30 flowers per meter of mixed shoots (FMMS). Nectarines reached the higher FD, around 50 FMMS, with 
the exception of 'Nectarine 24' (Fig. 4A). 'Tropic snow' and 'Hermosillo' were the only peach cultivars that were able to reach an FD like nectarines, whereas 'Flordastar', 'Fla 1-8 bis', and 'Nectarine 24 ' showed more than 30 FMMS. The remaining cultivars presented lower values of FD, the lowest one being 'Flavorcrest' (Fig. 4A). Flower density showed relatively low values in comparison with other researches. 'Springlady' peach cultivated under Mediterranean climatic conditions showed an FD 2.2-fold higher (51.1 flowers $\mathrm{m}^{-1}$ ) (González Rossia et al., 2007), whereas the average FD of 33 peach germplasm was 67 flowers $\mathrm{m}^{-1}$ in the highlands of central Mexico, with only two peach varieties that showed less than 30 flowers $\mathrm{m}^{-1}$ (Pérez, 2004).

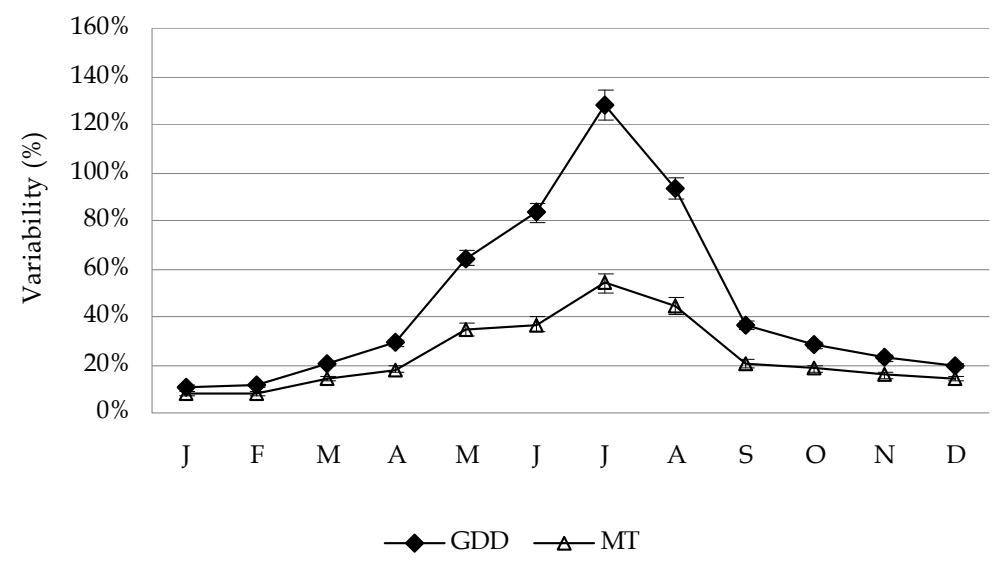

Fig. 3. Maximum variability of the monthly growing degree day (GDD) accumulation and the medium month temperature (MT) during a nine-year period (2002-2010) in the central area of Santa Fe, Argentina. GDD was calculated using a base temperature of $7^{\circ} \mathrm{C}$. Standard error is represented by the vertical bar.

Fruit set was around $30 \%$ in several varieties, with only three genotypes that reached over $40 \%$ of fruit set ('Flordastar', 'Flordaprince' and 'Flordaking') (Fig. 4B). 'Don Agustín', 'Lara', 'Nectarine 22' and 'Nectarine 29' were the low chilling varieties that showed the lowest fruit set, similar to that observed in high chilling ones (6.3\% to 15.7\%) (Fig. 4B).

Fruit size showed great differences among genotypes. 'Hermosillo' and 'Fla 1-8 bis' had the biggest fruit size, whereas six other varieties reached a fruit size near $120 \mathrm{~g} \mathrm{fruit}^{-1}$ ('Early grande', 'Fla 1-8', 'Flordaking', 'June gold', 'Nectarine 22', and 'Tropic snow') (Fig. 4C). 'Flordastar' and nectarine 'Carolina' were the low chilling varieties that had the lower fruit size. High chilling varieties also showed low fruit size with the exception of 'June gold'. 'Flavorcrest' was not able to develop normal fruit, being small with a high percentage of aborted embryos. Fruit size was lower in this experiment than that observed in Valencia, Spain (Badenes et al., 1998), but these differences varied among varieties; it was slightly different for 'Tropic snow' but significant for 'Flordaking', 'Flordastar', and 'Flavorcrest'.

As a consequence of their better reproductive behavior, 'Hermosillo' and 'Tropic snow' had the highest fruit yield (Fig. 5). The other low chilling varieties $(\leq 450 \mathrm{CH})$ had lower fruit yield than these varieties. In 'Flordastar' and 'Carolina', fruit yield was mainly limited by fruit size, whereas in 'Don Agustín', 'Lara', 'Nectarine 22', 'Nectarine 24' and 'Nectarine 29', 
fruit yield was limited by fruit set. Fruit yield of high chilling requirement varieties $(\geq 500$ $\mathrm{CH}$ ) was insignificant due to its lower fruit set (Fig. 4B), and late fruit drop.
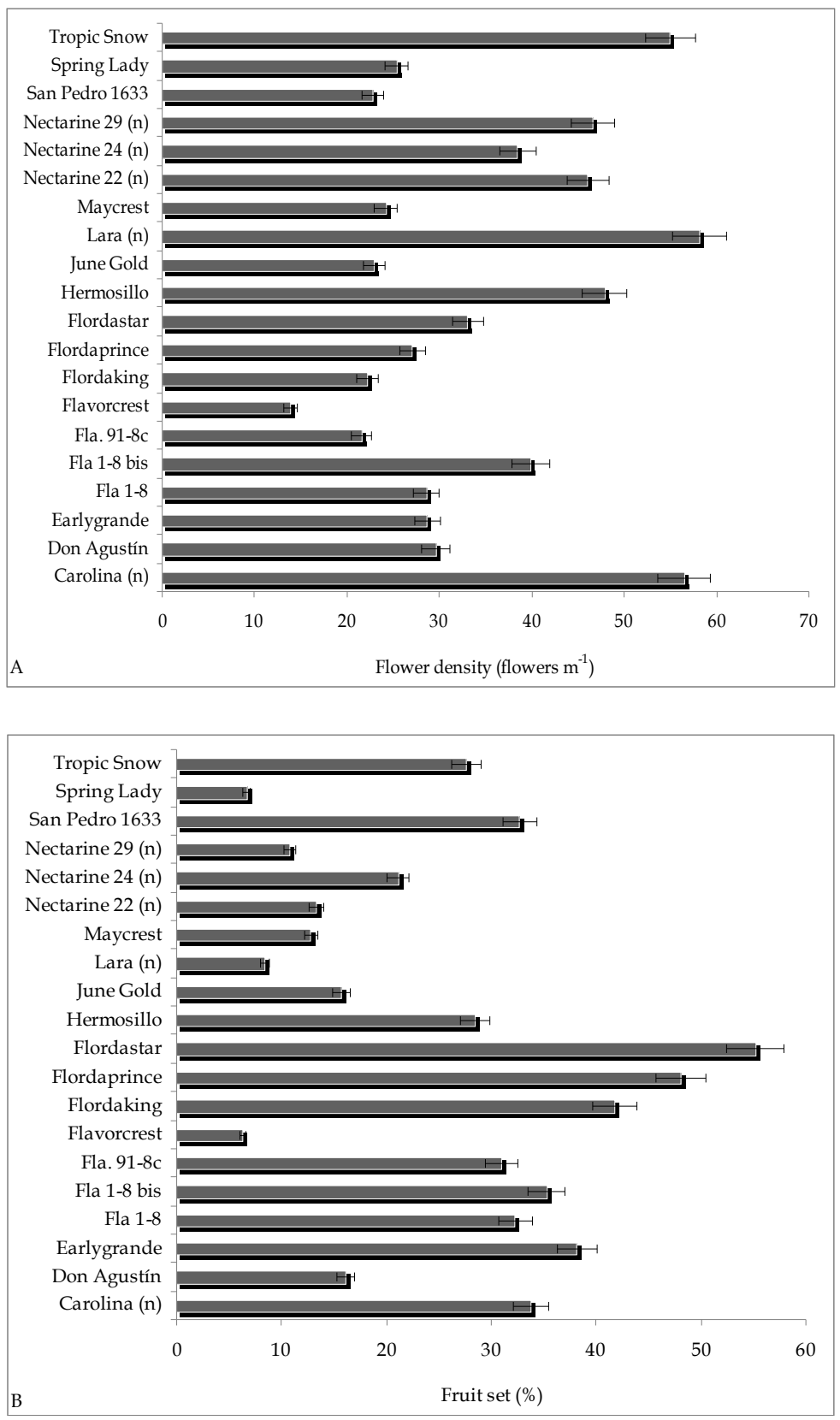
Influence of the Environmental Conditions, the Variety, and Different Cultural

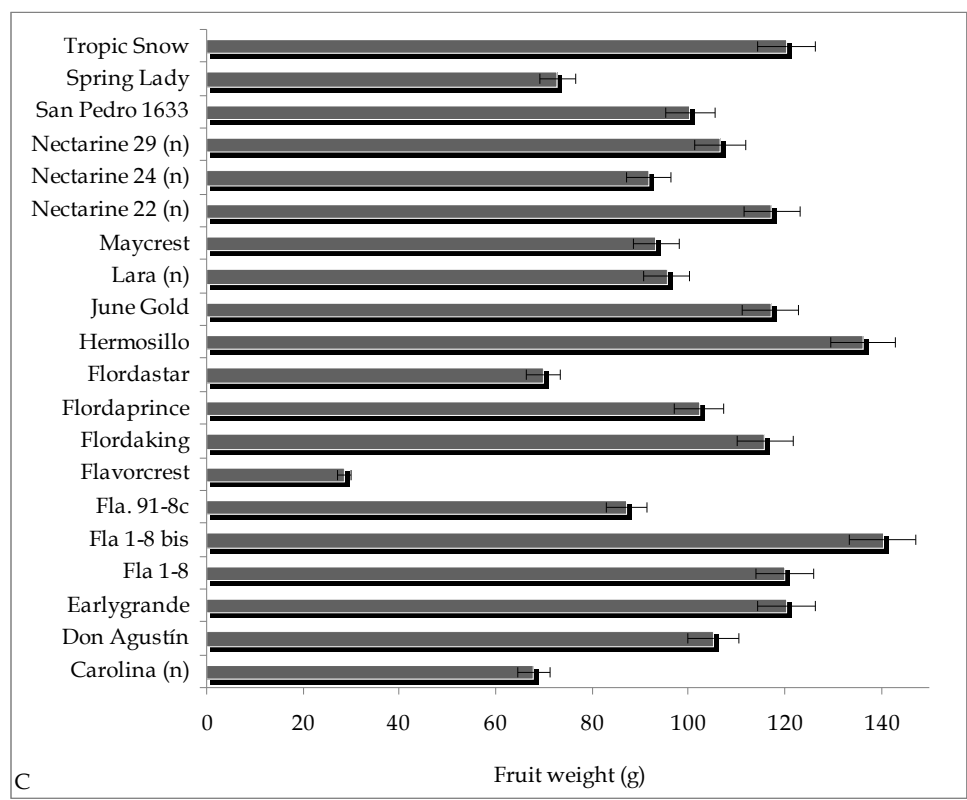

Fig. 4. Flower density (A), fruit set (B), and fruit weight (C) of different peach and nectarine (n) varieties grown in the central-east area of Santa Fe, Argentina.

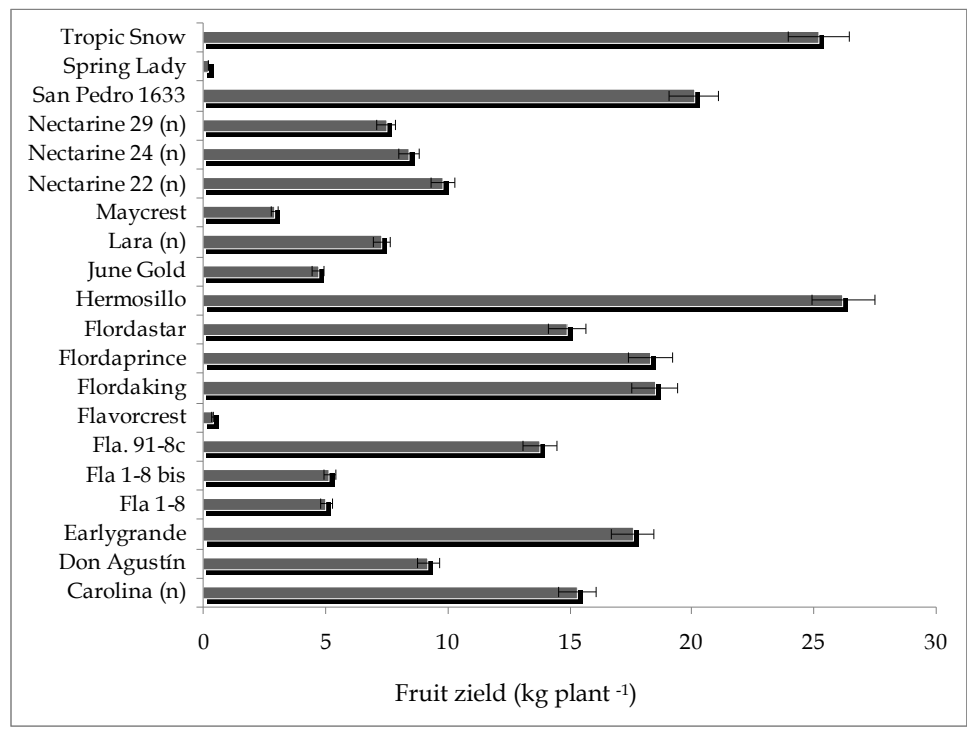

Fig. 5. Fruit yield of different peach and nectarine (n) varieties grown in the central-east area of Santa Fe, Argentina. Data are the means of a nine-year period (2002-2010) beginning with four-year-old plants, with the exception of 'Fla 1-8', 'Fla 1-8 bis', 'Nect. 22', 'Nect. 24', and 'Nect. $29^{\prime}$, which are the means of a three-year period. 
In the temperate fruit tree crops, the most critical phenological period affected by frost is from full bloom until fruit set (stages 71 and 72 in the $\mathrm{BBCH}$ scale for stone fruits) (Fideghelli, 1987). September $5^{\text {th }}$ is the average date for last frost occurrence in the central area of the province of Santa Fe (Panigatti, 1980). Consequently, in our experiment, blooming and fruit set took place during the period of frequent late frost occurrence for low chilling but not for high chilling varieties. However, although high chilling varieties can avoid spring frost, they showed a very low fruit yield because they were unable to cover its chilling requirement in the central area of Santa Fe (Gariglio et al., 2006a), explaining the negative correlation between flowering density, fruit set and crop load with the chilling requirement of the cultivar that was observed for peaches and nectarines grown in the region (Gariglio et al., 2009). In contrast, low chilling varieties showed a better adaptation in spite of the high risk of late winter frost, because these cultivars exhibited an extended blooming period and had a higher opportunity for fruit set after the occurrence of low temperature (Pérez, 2004). Furthermore, in the central area of Santa Fe, the Paraná River tempers the intensity and duration of frosts.

Low yield of the group of high chilling varieties can also be attributed to the reduction of the pollination and fertilization caused by relatively warm temperature occurrence at the time of flowering and fruit set as was mentioned for peach accessions with late blooming in the Mexican subtropics (Pérez, 2004).

\subsection{Modification of peach phenology caused by the time of autumn defoliation}

Artificial defoliation of 'Flordaking' peach performed at the beginning of natural leaf fall advanced sprouting and beginning of blooming of the next growing cycle by 15 days, in comparison with the control. This difference between treatments decreased to 8 days at full flowering and fruit set, and disappeared at harvest time. Furthermore, autumn defoliation did not affect the percentage of budbreak, but reduced fruit set $(-40 \%)$ and crop load at harvest $(-35 \%)$.

The depth of dormancy (MTB value) of floral buds from shoots excised during winter rest was highest at leaf fall for both treatments, and decreased during 65 days, remaining constant until the end of dormancy (Table 3). However, artificial defoliation reduced to half the depth of dormancy at leaf fall in comparison with the control. Differences between treatments diminished one month later, and it disappeared from 50 days after leaf fall to the end of dormancy (Table 3). The MTB value of vegetative buds was also affected by defoliation but the reduction was only $12 \%$ at leaf fall and the differences between treatments disappeared 20 days later.

Defoliation only modified MTB on shoots excised from the trees during the first 40-45 days after leaf fall because the endodormancy of 'Flordaking' peach is released at this time; the depth of dormancy (MTB value) of its buds did not decrease further over time, i.e. MTB does not show further decreases with chilling, indicating that buds are under eco-dormancy (Balandier et al., 1993; Dennis, 2003). Defoliation also reduced fruit set with regard to control trees, as in apple (Mohamed, 2008), perhaps for the major probability of lower temperature occurrence and lower activity of pollinators during flowering.

The role of the presence of leaves during autumn in the onset and progression of dormancy is attributed to the perception of the photoperiodic stimulus via phytochrome-mediated signaling that triggers the onset of dormancy of deciduous trees under a shortening 
photoperiod (Rinne \& van der Schoot, 2004), mainly by the stimulation of the synthesis of ABA and other growth inhibitors (Tanino, 2004). Thus, defoliation near the period of natural leaf fall interferes with the physiological process of the onset of dormancy, explaining the great reduction of the depth of dormancy (Table 3) and the advances of blooming in the next spring that was observed in this work.

\begin{tabular}{lccc}
\hline Time of shoot & \multicolumn{2}{c}{ MTB (days) } & \multirow{2}{*}{ Significance } \\
\cline { 2 - 3 } extraction & Control & Defoliation & $*$ \\
\hline May 3 & 47.0 & 22.5 & $*$ \\
May 24 & 27.1 & 20.0 & $\mathrm{~ns}$ \\
June 22 & 11.5 & 11.0 & $\mathrm{~ns}$ \\
July 7th & 7.2 & 8.5 & $\mathrm{~ns}$ \\
July 29th & 6.5 & 8.8 & \\
\hline
\end{tabular}

* = significant; $\mathrm{ns}=$ not significant at $P \leq 0.05$

Table 3. Effect of autumn defoliation on mean time to budbreak (MTB) of floral buds from shoots of 'Flordaking' peach excised at different times of winter rest period and forced at a constant temperature $\left(20^{\circ} \mathrm{C}\right)$.

\subsection{Modification of peach behavior caused by summer pruning}

\subsubsection{Summer pruning and autumn defoliation}

Summer pruning showed a great effect on the time of autumn leaf fall, and blooming in the next spring. Natural leaf fall of 'Flordaking' peach began at the end of March and pruning performed after harvest delayed it 11 days (Fig. 6). Summer pruning after harvest also changed the patterns of defoliation, which showed significant differences between treatments until late April. However, complete defoliation was reached during the first fortnight of May in both treatments (Fig. 6).

When pruning was performed at a different time of the growing cycle using the cv. 'Early grande', it was observed that autumn defoliation was also delayed by summer pruning after harvest (November), regardless of whether the trees were pruned again during winter or were only summer pruned (Fig. 7). On the other hand, autumn defoliation occurred earlier when peach trees were pruned at the beginning of February or February and June; these trees reached $50 \%$ of defoliation in the middle of February, one month earlier than trees pruned during April or June, and nearly two months earlier in comparison with trees pruned during November (Fig. 7). Pruning performed at the beginning of April did not affect the evolution of leaf drop in comparison with trees that were pruned only during the winter period (Control = Jun-P, Fig. 7).

In Japan, summer pruning after harvest also delayed leaf fall by two months in comparison with non-summer pruned trees (Hossain et al., 2005). Leaf senescence is an active process programmed by genetic information and modulated by several plant hormones and environmental factors, but basically it is an age dependent process (Srivastava, 2002). Consequently, the delay of leaf fall caused by summer pruning can be explained by the presence of younger leaves at the time of leaf fall in trees that were summer-pruned after harvest (November) in comparison with trees that were not summer-pruned or were pruned in February. Summer pruning after harvest but not summer pruning at the beginning of 
February induces the appearance of new axes which are able to continue growing almost to the end of the vegetative period (Médiène et al., 2002; Weber et al., 2011; Weibel et al., 2003).

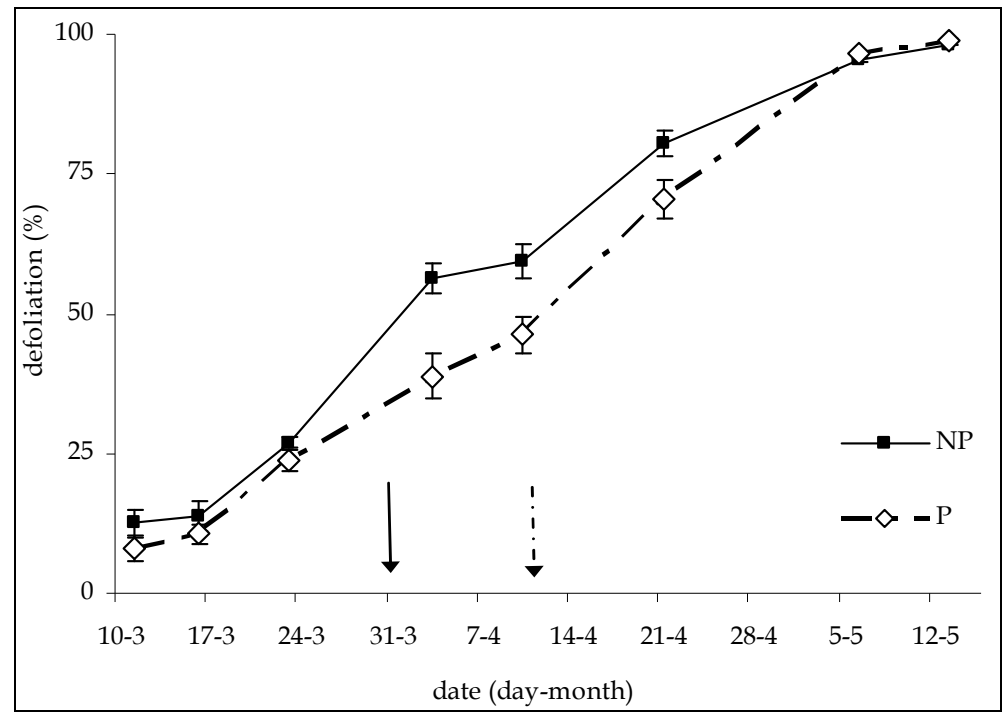

Fig. 6. Pattern of leaf senescence (percent of leaf defoliation) of peach trees, cv. 'Flordaking', pruned $(\mathrm{P})$ or not pruned (NP) after harvest. Vertical bars represent the standard error for each sample. Arrows indicate the time at which each treatment reached $50 \%$ of defoliation.

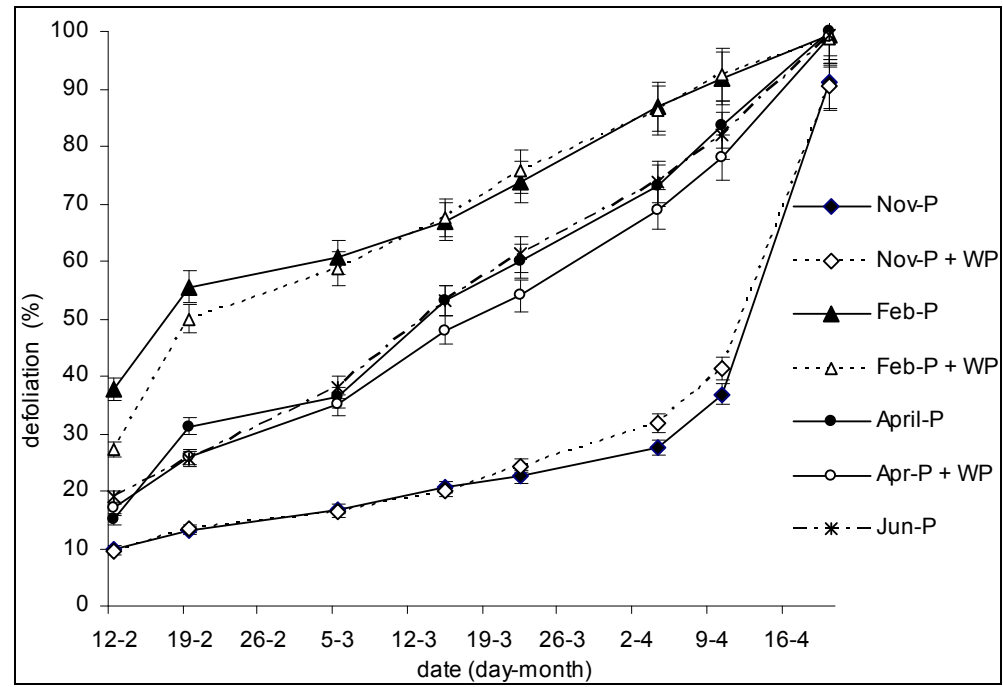

Fig. 7. Pattern of autumn defoliation evolution in 'Early grande' peach trees pruned only in summer (Nov-P; Feb-P; Apr-P), both in summer and winter periods (Nov-P + WP; Feb-P + WP; Apr-P + WP), or only during winter (Jun-P, control treatment). Data correspond to 2007. 


\subsubsection{Summer pruning and time of blooming}

As was discussed previously for the autumn defoliation experiment, the time of leaf fall can also affect dormancy induction and release. Thus, the delay of leaf senescence caused by summer pruning after harvest can explain why this treatment delayed the occurrence of the different phenological stages of flower buds of 'Flordaking' peach in the next spring. Nonsummer pruned plants reached the beginning of flowering eight days before and were harvested three days earlier in comparison with summer-pruned plants (Table 4).

\begin{tabular}{|c|c|c|c|c|}
\hline \multirow{2}{*}{ Phenological growth stage } & \multirow{2}{*}{$\mathrm{BBCH}^{1}$} & \multicolumn{2}{|c|}{ Date } & \multirow{2}{*}{$\begin{array}{c}\text { Difference } \\
\text { (Days) }\end{array}$} \\
\hline & & NP & $\mathrm{P}$ & \\
\hline Full flowering & 65 & August 28th & September $05^{\text {th }}$ & +8 \\
\hline Fruit set & $69-72$ & September $11^{\text {th }}$ & September $14^{\text {th }}$ & +3 \\
\hline Harvest & 87 & November $10^{\text {th }}$ & November $13^{\text {th }}$ & +3 \\
\hline First leaves emerging & 10 & August $15^{\text {th }}$ & August 18th & +3 \\
\hline
\end{tabular}

(1)Phenological growth stage according to BBCH (Meiers et al., 1994)

Table 4. Main phenological events of peach trees, cv. 'Flordaking', pruned (P) or not pruned (NP) after harvest.

However, the modification of the tree phenology by summer pruning in relation with autumn defoliation was easier to observe in the experiment in which 'Early grande' peach was pruned at a different time of the growing cycle. The treatments of pruning that delayed autumn defoliation (Nov-P) also delayed spring bloom by 7 to 10 days in comparison with the control; on the other hand, the treatments that advanced autumn defoliation (Feb-P) also advanced spring bloom by 6 to 8 days (Table 5). This effect was explained by the modification of the depth of dormancy caused by summer pruning; pruning during February (late summer) showed the lowest depth of dormancy at leaf fall in comparison with the other treatments, and this effect was attributed to the early defoliation caused by pruning (Lloyd \& Firth, 1993; Weber et al., 2010). Trees defoliated closer to the time of natural defoliation advanced the blooming date over naturally defoliated controls; however, this effect was variable when defoliation occurred early (Lloyd \& Firth, 1990).

\begin{tabular}{lc}
\hline Treatment & Full flowering deviation (days) \\
\hline Nov-P & +10 \\
Nov-P + WP & +7 \\
Feb-P & -8 \\
Feb-P + WP & -6 \\
April-P & -1 \\
April-P + WP & 0 \\
\hline
\end{tabular}

Table 5. Phenology variation (days) regarding control (winter pruning; Jun-P) at the phenological stage of full flowering in peach trees, $\mathrm{cv}$. 'Early grande', pruned only during summer (Nov-P; Feb-P; Apr-P), or both in summer and winter period (Nov-P + WP; Feb-P + WP; Apr-P + WP). 


\subsubsection{Relationships between summer pruning, autumn defoliation and time of blooming}

Summer pruning treatments performed at a different time of the growing cycle modified the time of autumn defoliation and the time of spring blooming with a strong and direct relationship between both variables (Fig. 8). Treatments of pruning that advance autumn leaf fall also advanced spring bloom whereas treatment that delayed autumn defoliation also delayed flowering in the next spring. According to the slope value of the fit line (Fig. 8), the time of spring flowering was modified in one day when the time of autumn defoliation was changed in three days. However, this effect was clearly observed in only one of three years of experimentation.

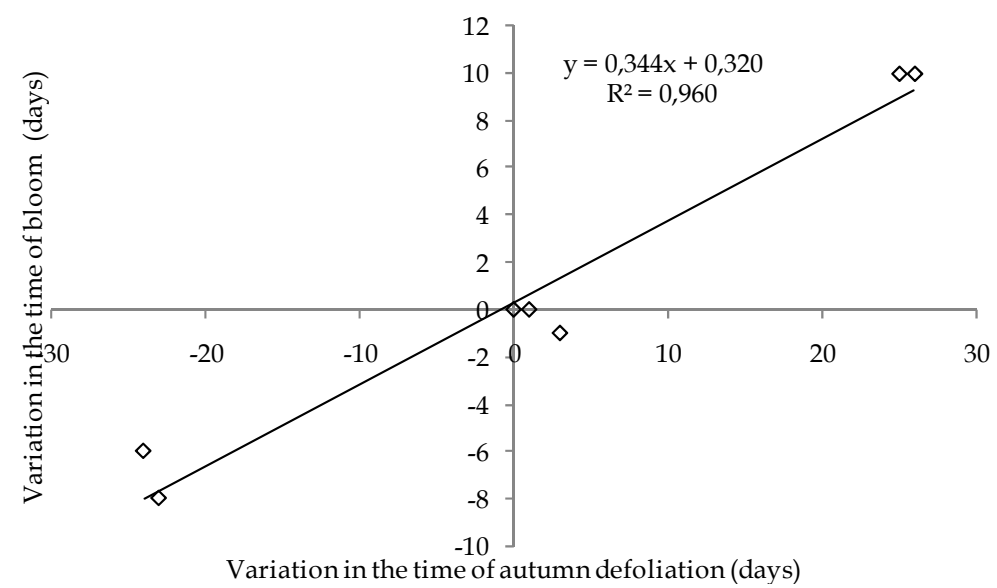

Fig. 8. Relationships between the modification of the time of autumn defoliation and the consequent variation in the time of blooming in the next spring caused by summer pruning performed at a different time of the growing cycle. Data were expressed in comparison with trees that were pruned during winter rest, in peach trees, cv. 'Early grande'.

These results showed the relationships between summer pruning and artificial defoliation on the time of leaf fall, and provide further evidence of the importance of the presence of leaf during autumn and the time of leaf abscission on the phenology of low chilling peach varieties in the next spring. Any cause (abiotic, biotic, cultural practices) that modifies the time of leaf fall occurrence changes the period of tree exposition to the short day inductive condition, and may alter the physiological process of dormancy in temperate fruit trees (Heide, 2008). As low chilling peach also had a low depth of dormancy (Citadin et al., 2001; Gariglio et al., 2006b), any modification, however small, in the depth of dormancy seems to have a great effect on the tree phenology in the next spring. These observations can also explain different results obtained with the defoliation technique on the time of blooming in the next spring (Citadin et al., 2001; Egea et al., 2003; Ganji Moghadam \& Mokhtarian, 2006). In addition, it is expected that the treatments that reduce the depth of dormancy can increase the variability of peach phenology as was previously discussed when the phenological variability of low and high chilling requirement varieties were mentioned (see Fig. 2). Otherwise, the time of sprouting was less affected by summer pruning in relation with blooming (Table 4). 
It is important to mention that summer pruning performed during February caused an important density of flowering during the autumn period. In the middle of April, Feb-P trees showed open flowers in $21 \%$ of its mixed shoots, causing a budbreak that reached up to $35 \%$ of the flower buds of these branches. No vegetative budbreak during the autumn period was stimulated by this pruning. Clearly, the occurrence of autumn flowering was due to the reduction on the depth of dormancy caused by summer pruning performed at the beginning of February. Furthermore, as flower bud had lower depth of dormancy than leaf bud (Gariglio et al., 2006b), blooming but not sprouting was stimulated by summer pruning at the beginning of February.

\subsubsection{Summer pruning on vegetative and reproductive traits of peach trees}

The pattern of the percentage of sprouting evolution was also modified by summer pruning after harvest (Fig. 9); vegetative budbreak increased faster in non-summer pruned trees but not in pruned ones. Non-summer pruned trees reached $50 \%$ of sprouting before August $25^{\text {th }}$ whereas summer pruned plants arrived at this threshold value during the second week of September. The final percentage of vegetative budbreak was slightly above $60 \%$ in both treatments (Fig. 9). This behavior of vegetative budbreak observed in summer pruned trees can be a consequence of the delays on the time of sprouting and blooming of the next growing cycle, and on the increases of the depth of dormancy of vegetative and reproductive buds caused by summer pruning after harvest, mentioned and discussed previously.

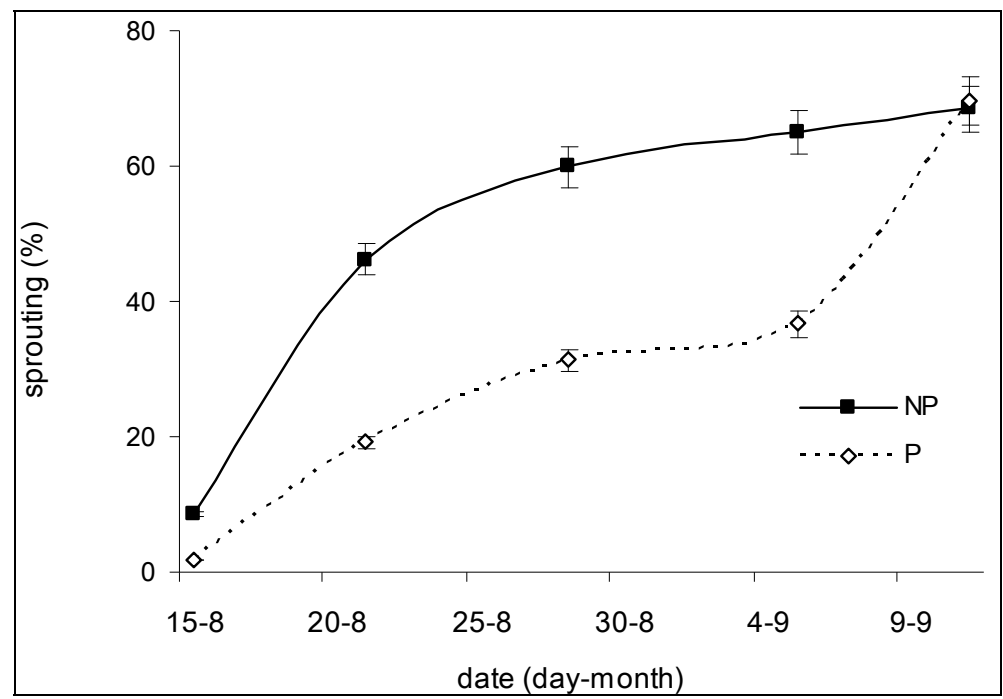

Fig. 9. Pattern of the vegetative budbreak evolution at the beginning of the growing cycle in 'Flordaking' peach trees that were pruned (P) or not pruned (NP) after harvest.

Summer pruning after harvest significantly reduced fruit size at the beginning of the fruit growth period $(-23.7 \%)$, but this difference diminished from the last 15 days of fruit growth, becoming insignificant at harvest. 
In relation to the reproductive traits of peach trees, summer pruning after harvest did not affect flower density and fruit set of 'Flordaking' peach. Floral induction of low and medium chilling peach varieties occurred after harvest (González-Rossia et al., 2007), and summer pruning performed at this time stimulated vegetative growth rate (Weber et al., 2011). Therefore, as vegetative growth and floral induction are a competitive process (Reig et al., 2006), it is expected that summer pruning after harvest caused a reduction on the flower density of pruned trees. However, summer pruning stimulates vegetative growth, but also improves light penetration into the canopy (Marini, 2003; Marini \& Barden, 1982; Weber et al., 2011) which is required for floral induction and floral bud differentiation (Marini, 2003). Thus, it is possible that both effects may be neutralized and flower intensity would not be affected.

Although pruning treatment did not significantly affect fruit load over three years of experimentation (NP, 231 and P, 259 fruits per plant in average), it did significantly affect the distribution of the fruits in the plant height, increasing the proportion of those located in the intermediate stratum of the plant height $(+10 \%$ to $+40 \%)$, and decreasing those of the upper one $(-45 \%$ to $-50 \%)$. This effect is related to the major proportion of reproductive shoots observed in the medium stratum for summer pruned trees in comparison with nonpruned ones (Weber et al., 2011). This effect of pruning is explained by an improvement of the internal distribution of light (Stebbins, 1997; Weber et al., 2011) and a change in the dominant position of vegetative growth which is transferred from the apical to the basal zone of the canopy after pruning (Li et al., 1994a).

Unlike the previous experiment, summer pruning performed at a different time of the growing cycle using 'Early grande' peach caused a significant modification on fruit set, and consequently on the number of fruits per plant at harvest. Both variables (fruit set and number of fruit per plant) were significantly reduced by winter pruning during the years characterized by light late frost occurrence (Table 6). In this experiment, trees that were only pruned during the summer period showed a fruit set from 1.25- to 3.2-fold higher and the number of fruit per plant was 1.17- to 5.5-fold higher in comparison to trees that were pruned during winter. This effect was not observed during years without late frost occurrence.

\begin{tabular}{lcc}
\hline Treatment & Fruit set (\%) & Fruits/plant \\
\hline Jun-P & $3.8 \mathrm{c}$ & $77 \mathrm{~d}$ \\
Nov-P & $16.0 \mathrm{a}$ & $293 \mathrm{a}$ \\
Nov-P + WP & $4.1 \mathrm{c}$ & $87 \mathrm{~d}$ \\
Feb-P & $12.2 \mathrm{a}$ & $206 \mathrm{~b}$ \\
Feb-P + WP & $4.9 \mathrm{c}$ & $54 \mathrm{e}$ \\
Apr-P & $6.2 \mathrm{~b}$ & $102 \mathrm{c}$ \\
Apr-P + WP & $5.0 \mathrm{c}$ & $55 \mathrm{e}$ \\
\hline
\end{tabular}

Table 6. Fruit set and total fruits per plant in 'Early grande' peach trees that were pruned in summer (Nov-P, Feb-P and Apr-P), both in summer and winter periods (Nov-P + WP, Feb-P $+\mathrm{WP}$ and Apr-P + WP) or only during winter (Jun-P, control). Data are the means of two years (2007 and 2008), characterized by light spring frost occurrence. Means with different letters in the same column differ significantly $(P \leq 0.05)$. 
This effect of winter pruning on fruit set is difficult to explain because the treatments showed different times of blooming (Table 5) and the sensitivity to frost increases with the development of the flowers (Racskó et al., 2007); however, comparing trees that received pruning only during the summer period with trees that were pruned twice (summer and winter time) and that reached blooming at the same time (Nov-P and Nov-P + WP; Feb-P and Feb-P + WP; Apr-P, Apr-P + WP, and Jun-P), showed that treatments that received winter pruning had a lower fruit set (Table 6). It is also possible to demonstrate that this effect is due to the winter pruning and not by the number of prunings that received each treatment because the control (Jun-P) received only one pruning during winter and showed the lowest fruit set in comparison with trees that received one pruning treatment during the growing cycle or two pruning treatments (summer and winter pruning).

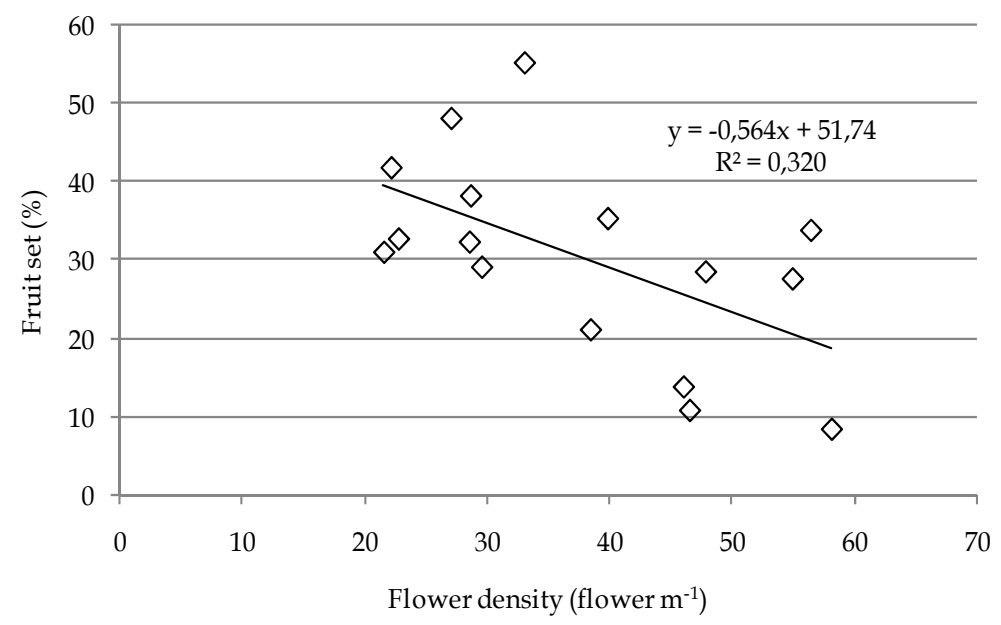

Fig. 10. Relationship between flower density and fruit set of different low chilling peach cultivars growing in the central-east area of Santa Fe, Argentina. Data are the means of a nine-year period (2002-2010).

This negative effect of winter pruning on fruit set was previously observed when long pruning and short pruning techniques were evaluated in peach trees growing in China ( $\mathrm{Li}$ et al., 1994b; Singh \& Daulta, 1985). They observed that long pruning increased resistance of flowers to late frost in spring because the high quality buds that have a higher resistance to frost were generally situated at the mid region of the shoot, and these buds were eliminated when short pruning was practiced ( $\mathrm{Li}$ et al., 1994b). However, in our experiments long pruning was practiced during winter and consequently the importance of bud quality in the mid region of the shoot cannot explain our results. The competence between growing organs caused a great diminution of fruit set in citrus (Agustí, 2003) and other subtropical crops such us mango (Ramírez \& Davenport, 2010). Fruit set of stone fruits seems to be unaffected by flower intensity (González-Rossia et al., 2007), but despite this we found a negative tendency of fruit set of peach with the flower density of the cultivars (Fig. 10); fruit set decreased by half ( $40 \%$ to $20 \%$ ) when the flower density increased from 20 to 60 flowers per meters of mixed shoots. Furthermore, we did not observe changes of flower density caused by pruning treatments. Instead, there is good evidence that winter pruning 
stimulates vegetative growth ( $\mathrm{Li}$ et al., 1994a; Marini, 2003) of deciduous trees, and that competition for carbohydrates from shoot growth accentuates early fruit abscission, even at a relatively low crop load (Racskó et al., 2007).

In low chilling peach a great proportion of floral bud abortion was observed when excised shoots received excessive chilling that stimulated vegetative growth when they were forced at $25^{\circ} \mathrm{C}$ (Gariglio et al., 2006b). Similar effects were induced by the use of hydrogen cyanamide to stimulate budbreak under conditions of low chilling accumulation (Lloyd \& Firth, 1993). Thus, it is possible that winter pruning diminishes fruit set under suboptimal low temperature conditions by increasing competition between vegetative and reproductive growth.

\section{Conclusion}

Low chilling peach and nectarine varieties $(\leq 450 \mathrm{CH})$ grown in the central area of Santa Fe, Argentina, showed high flower density, fruit set, number of fruit per plant, and consequently, higher fruit yield with regard to peach varieties with higher chilling requirement $(>500 \mathrm{CH})$. The phenology of high chilling requirement varieties had the advantage that blooming and fruit set occurred after the period of risk of late frost occurrence; however, they did not satisfy their chilling requirement, showing an inadequate vegetative and reproductive behavior. Phenology variability between years decreased with the advance of the growing cycle and with the chilling requirement of the variety, and this behavior is explained by the low depth of dormancy of low chilling peach, and the high variability of the temperature during the period of dormancy and blooming of low chilling peach.

Artificial defoliation at the beginning of leaf fall and summer pruning greatly affect phenology of low chilling peach. Summer pruning delayed autumn leaf fall when it was performed after harvest (November), but advanced leaf senescence when it was done at the beginning of February. The time of blooming and sprouting in the next spring was directly related to the time of autumn leaf fall. This effect can be explained by the role of the presence of leaf on the onset and progression of dormancy; thus, the advances of leaf fall (artificial autumn defoliation and summer pruning during February) reduce the depth of dormancy, advancing blooming and sprouting, while the delay in leaf fall (summer pruning during November) increases the depth of dormancy of low chilling peach, delaying blooming and sprouting in the next spring. As a consequence, by changing the time of autumn leaf fall through the use of different cultural practices such as artificial defoliation or summer pruning, it is possible to modify by nearly 20 days the time of flowering in the next spring, allowing growers to improve precocity or to avoid late frost occurrence, among other possible objectives.

\section{References}

Agustí, M. (2003). Citricultura. Second Edition. Mundi Prensa, ISBN 9788484761587, Madrid, Spain

Alayón Luaces, P., Rodríguez, V.A. \& Bertuzzi, S.M. (2004). El cultivo del manzano (Malus domestica Borkh.) en Corrientes. Primer año de investigación. Comunicación científica y tecnológica A-029, pp. 1-4. Accessed November 2007, Available from: http://www.unne.edu.ar/Web/cyt/com2004/5-Agrarias/A-029.pdf 
Badenes, M.L., Martínez-Calvo, J. \& Llacer, G. (1998). Estudio comparativo de la calidad de los frutos de 26 cultivares de melocotonero de origen norteamericano y dos variedades-población de origen español. Investigación Agraria: Producción y Protección Vegetal, Vol.13, No.1-2, (May 1997), pp. 57-70, ISSN 0213-5000

Balandier, P., Bonhomme, M., Rageau, R., Capitan, F. \& Parisot, E. (1993). Leaf bud endodormancy release in peach trees: evaluation of temperature models in temperate and tropical climate. Agricultural and Forest Meteorology, Vol.67, No.1-2, (December 1993), pp. 95-113, ISSN 0168-1923

Broadhead, J.S., Ong, C.K. \& Black, C.R. (2003). Tree phenology and water availability in semi-arid agroforestry systems. Forest Ecology and Management, Vol.180, No.1, (July 2003), pp. 61-73, ISSN 0378-1127

Carra de Toloza, M.S. (2001). Selección de variedades de duraznos de mesa y nectarinos promisorios y recomendados para su cultivo en la provincia de Mendoza. Horticultura Argentina, Vol.20, No.48, (October 2001), pp. 44, ISSN 0327-3431

CFI. Consejo Federal de Inversiones. (2011). Sector frutícola argentino. Accessed June 2011, Available from: http:/ / www.cfired.org.ar/Default.aspx?nId=328

Citadin, I., Raseira, M.C.B. \& Quezada, A.C. (1998). Substrato para conservacao de ramos destacados de pessegueiro Prunus persica L. (Bastch). Agropecuária Clima Temperado, Vol.1, No.1, (February 1998), pp. 55-59, ISSN 1415-6822

Citadin, I., Raseira, M.C.B., Verter, F.G. \& Baptista da Silva, J. (2001). Heat requirement for blooming and leafing in peach. HortScience, Vol.36, No.2, (May 2001), pp. 305-307, ISSN 0018-5345

Couvillon, G. \& Lloyd, D. (1978). Summer defoliation effects on spring bud development. HortScience, Vol.13, pp. 53-54, ISSN 0018-5345

Dennis Jr., F.G. (2002). Dormancy: Manifestations and causes. In: Handbook of plant and crop physiology, Pessarakli, M. (Ed.), Chapter 8, pp. 161-179, Marcel Dekker, ISBN 9780824705466, New York

Dennis Jr., F.G. (2003). Problems in standarizing methods for evaluating the chilling requirements for the breaking dormancy in buds of woody plants. In: Standarizing methods for evaluating the chilling requirements to break dormancy in sedes and buds (Including Geophytes). HortScience, Vol.38, No.3, (June 2003), pp. 347-350, ISSN 0018-5345

Egea, J., Orgega, E., Martínez-Gómez, P. \& Dicenta, F. (2003). Chilling and heat requirement of almond cultivars for flowering. Environmental and Experimental Botany, Vol.50, No.1, (August 2003), pp. 79-85, ISSN 0098-8472

Erez, A., Faust, M. \& Line, M. (1998). Changes in water status in peach buds on induction, development and release from dormancy. Scientia Horticulturae, Vol.73, No.2-3, (March 1998), pp. 111-123. ISSN 0304-4238

Faust, M. (1989). Physiology of temperate zone fruit trees. John Wiley \& Sons, ISBN 0471817813, New York

Faust, M., Erez, A., Rowland, L.J., Wang, S.Y. \& Norman, H.A. (1997). Bud dormancy in perennial fruit trees: Physiological basis for dormancy induction, maintenance, and release. HortScience, Vol.32, No.4, (July 1997), pp. 623-629, ISSN 0018-5345

Fideghelli, C. (1987). El Melocotonero. Ediciones Mundi Prensa, ISBN 84-7114-166-3, Madrid

Ganji Moghadam, A. \& Mokhtarian, A. (2006). Delaying apricot (cv Shahroudi) flower induction by growth regulators application. Journal Applied Sciences, Vol.6, No.2, pp. 266-269, ISSN 1812-5654 
Gariglio, N.F., Baldi, B. \& Enrique, A. (1999). Comportamiento del duraznero en la región central de Santa Fe. VII Jornadas de Jovens Pesquisadores do Grupo Montevideo. Ciência para a Paz. Libro de resúmenes, p. 21

Gariglio, N., Dovis, V.L., Leva, P., García, M.S. \& Bouzo, C.A. (2006a). Acumulación de Horas de Frío en la zona centro-oeste de Santa Fe (Argentina) para frutales caducifolios. Horticultura Argentina, Vol.25, No.58, (June 2006), pp. 26-32, ISSN 0327-3431

Gariglio, N.F., González Rossia, D.E., Mendow, M., Reig, C. \& Agustí, M. (2006b). Effect of artificial chilling on the depth of endodormancy and leaf and flower budbreak of peach and nectarine cultivars using excised shoots. Scientia Horticulturae, Vol.108, No.4, (May 2006), pp. 371-377, ISSN 0304-4238

Gariglio, N., Mendow, M., Weber, M., Favaro, M.A., González-Rossia, D. \& Pilatti, R.A. (2009). Phenology and reproductive traits of peaches and nectarines in central-east Argentina. Revista Scientia Agrícola, Vol.66, No.6, (November 2009), pp. 757-763, ISSN 0103-9016

González Rossia, D., Reig, C., Juan, M. \& Agustí, M. (2007). Horticultural factors regulating effectiveness of GA3 inhibiting flowering in peaches and nectarines (Prunus persica L. Batsch). Scientia Horticulturae, Vol.111, No.4, (February 2007), pp. 352-357, ISSN 0304-4238

Gorny, J.R., Hess-Pierce, B. \& Kader, A.A. (1999). Quality changes in fresh-cut peach and nectarine slices as affected by cultivar, storage atmosphere and chemical treatments. Journal of Food Science, Vol.64, No.3, (May 1999), pp. 429-432, ISSN 17503841

Heide, O.M. (2008). Interaction of photoperiod and temperature in the control of growth and dormancy of Prunus species. Scientia Horticulturae, Vol. 115, No. 3, (February 2008), pp. 309-314, ISSN 0304-4238

Hossain, A.B.M.S., Mizutani, F., Onguso, J.M. \& Yamada, H. (2005). Effect of summer and winter pruning of peach as slender spindle bush type on growth, yield and quality of fruit. Journal of Applied Horticulture, Vol.7, No.1, pp. 11-15. ISSN 0972-1045

INDEC. (2002). Censo Nacional Agropecuario. Accessed November 2005. Available from: http://www.indec.mecon.gov.ar/agropecuario/cna_principal.asp

INIA Salto Grande. (2003). Reunión anual de frutales de carozo. Salto Grande. Accessed February 2006. Available from:

http://www.inia.org.uy/publicaciones/documentos/sa/ad/2003/ad_334.pdf

Kudo, G. (2006). Flowering phenologies of animal-pollinated plants: reproductive strategies and agents of selection. In: Ecology and evolution of flowers, Harder, L.D. \& Barrett, S.C.H., eds, Chapter 8, pp. 139-158, Oxford University Press, ISBN 978-0-19-8570851 , New York, USA

Lang, G.A. (1996). Plant Dormancy: Physiology, Biochemistry and Molecular Biology, CAB International, ISBN 0851989780, Wallingford, UK

Li, S., Zhang, X., Meng, Z. \& Wang, X. (1994a). Responses of peach trees to modified pruning. I. Vegetative growth. New Zealand Journal of Crop and Horticultural Science, Vol.22, No.4, (May 1994), pp. 401-409, ISSN 0114-0671

Li, S., Zhang, X., Meng, Z., Wang, X. \& Liu, G. (1994b). Responses of peach trees to modified pruning. 2. Cropping and fruit quality. New Zealand Journal of Crop and Horticultural Science, Vol.22, No.4, (May 1994), pp. 411-417, ISSN 0114-0671 
Lieth, H. (1974). Phenology and Seasonality Modelling. (Ecological Studies-Analysis and Synthesis Series, Vol 8). Springer, ISBN 0387065245, Berlin, Germany

Loyd, J. \& Firth, D. (1990). Effect of defoliation time on depth of dormancy and bloom time for low-chill peaches. HortScience, Vol.25, No.12, (December 1990), pp. 1575-1578, ISSN 0018-5345

Lloyd, J., Firth, D. (1993). Effect of hydrogen cyanamide and promalin on flowering, fruit set and harvest time of 'Flordaprince' peach (Prunus persica (L.) Batsch) in subtropical Australia. Journal of Horticultural Science, Vol.68, No.2, pp. 177-183

Marini, R.P. (2003). Peach fruit weight, yield, and crop value are affected by number of fruiting shoots per tree. HortScience, Vol.38, Nro.4, (July 2003), pp. 512-514, ISSN 0018-5345

Marini, R.P. \& Barden, J.A. (1982). Growth and flowering of vigorous apple trees as affected by summer or dormant pruning. J. Amer. Soc. Hort. Sci., Vol.107, No.1, (January 1982), pp. 34-39, ISSN 0003-1062

Médiène, S., Jordan, M.O., Pages, L., Le Bot, J. \& Adamowicz, S. (2002). The influence of severe shoot pruning on growth, carbon and nitrogen status in young peach trees (Prunus persica). Tree Physiology, Vol.22, No.18, (May 2002), pp. 1289-1296, ISSN 0829-318X

Meier, U., Graf, H., Hack, H., Hess, M., Kennel, W., Klose, R., Mappes, D., Seipp, D., Stauss, R., Streif, J. \& Van Den Boom, T. (1994). Phänologische entwick-lungsstadien des kernobstes (Malus domestica Borkh. und Pyrus communis L.), des steinobtes (PrunusArten), der johannisbeere (Ribes-Arten) und der erdbeere (Fragaria $\times$ ananassa Dutch.). Nachrichtenbl Deutsch Pflazenschutzd, Vol.46, No.7, pp. 141-153

Mohamed, A.K.A. (2008). The effect of chilling, defoliation and hydrogen cyanamide on dormancy release, bud break and fruiting of Anna apple cultivar. Scientia Horticulturae, Vol.118, No.1-2, (September 2008), pp. 25-32, ISSN, 0304-4238

Ortiz de Zárate, V.G., Güemes, D.R., Piagentini, A.M., Gariglio, N.F. \& Pirovani, M.E. (2007). Comparación de la calidad de duraznos de diferentes variedades cultivadas en la región Centro-Este de la provincia de Santa Fe. Revista FAVE-Ciencias Agrarias, Vol.5/6, No.1-2, (November 2006), pp. 27-33, ISSN 1666-7719

Panigatti, J.L. (1980). Consideraciones sobre el clima del centro-oeste de la provincia de Santa Fe. INTA, Estación Experimental Regional Agropecuaria Rafaela. Boletín interno de divulgación No.15

Pérez, S. (2004). Yield stability of peach germplasm differing in dormancy and blooming season in the Mexican subtropics. Scientia Horticulturae, Vol.100, No.1-4, (March 2004), pp. 15-21, ISSN, 0304-4238

Petri, J.L., Hawerroth, F.J. \& Leite, G.B. (2008). Fenologia de espécies silvestres de macieira como polinizadoras das cultivares Gala e Fuji. Revista Brasileira de Fruticultura, Vol.30, No.4, (December 2008), pp. 868-874, ISSN 0100-2945

Ramírez, F. \& Davenport, T.L. (2010). Mango (Mangifera indica L.) flowering physiology. Scientia Horticulturae, Vol.126, No.2, (September 2010), pp. 65-72, ISSN, 0304-4238

Racskó, J., Leite, G.B., Petri, J.L., Zhongfu, S., Wang, Y., Szabó, Z., Soltész, M. \& Nyéki, J. (2007). Fruit drop: The role of inner agents and environmental factors in the drop of flowers and fruits. International Journal of Horticultural Science, Vol.13, Nro.3, pp. 1323. ISSN 1585-0404 
Reig, C., González-Rossia, D., Juan, M. \& Agustí, M. (2006). Effects of fruit load on flower bud initiation and development in peach. Journal of Horticultural Science $\mathcal{E}$ Biotechnology, Vol.81, No.6, (November 2006), pp. 1079-1085, ISSN 1462-0316

Rinne, P.L.H. \& van der Schoot, C. (2004). Cell-Cell communication as a key factor in dormancy cicling, In: Adaptations and responses of woody plants to environmental stresses, Arora, R. ed., pp. 113-156, The Haworth Press Inc., ISBN 81-8189-107-4, Binghamton, NY

Singh, D. \& Daulta, B.S. (1985). Studies on pruning severity in peach (Prunus persica Batsch) cv. Sharbati. I. Effect on sprouting, flowering, fruit set and fruit drop. Haryana journal of horticultural sciences, Vol.14, pp. 33-36, ISSN 0970-2873

Squire, G.R. (1990). The Physiology of Tropical Crop Production. CAB International, ISBN 0851986773, Wallingford, UK

Srivastava, L.M. (2002). Plant growth and development: Hormones and the environment, Academic Press, ISBN 0-12-660570-X, San Diego, USA

Stebbins, R.L. (1997). Training and Pruning commercial peach orchards. Oregon State University Extension Service. Accessed December 2003. Available from: htpp://www.eesc.orst.edu/agcomwebfile/edmat/EC1236.pdf

Tanino, K.K. (2004). Hormones and endodormancy induction in Woody plants, In: Adaptations and responses of woody plants to environmental stresses. Arora, R. ed., pp. 157-199, The Haworth Press, ISBN 81-8189-107-4, Binghamton, NY

Valentini, G. (2002). Variedades de duraznero y nectarina para el NE de la provincia de Buenos Aires. Accessed March 2004, Available from:

<http://www.inta.gov.ar/sanpedro/info/doc/fru/gv_003.htm>

Valentini, G. \& Arroyo, L. (2000). Variedades y Portainjertos. Jornada de Actualización en diferentes aspectos del cultivo de duraznero. INTA, Estación Experimental Regional Agropecuaria San Pedro, Libro de conferencias, pp. 2-8

Walser, R., Walker, D. \& Seeley, S. (1981). Effect of temperature, fall defoliation and gibberelic acid on the rest period of peach buds. J. Am. Soc. Hortic. Sci., Vol.106, No.1, (January 1981), pp. 91-94, ISSN 0003-1062

Weber, M.E., Pilatti, R., Sordo, M., Castro, D., Rista, L. \& Gariglio, N. (2010). La fecha de poda modifica la profundidad de la dormición y la intensidad de su ruptura en yemas vegetativas y reproductivas del duraznero, cv. 'Early grande'. Proceedings of XXXIII Congreso Argentino de Horticultura y I Simposio Internacional de la Frutilla, p. 214. Rosario, Argentina, September 2010

Weber, M.E., Pilatti, R., Sordo, M.H., García, M.S., Castro, D. \& Gariglio, N.F. (2011). Changes in the vegetative growth of the low-chill peach tree in response to reproductive shoot pruning after harvesting. New Zealand Journal of Crop $\mathcal{E}$ Horticultural Science, Vol.39, No.3 (September 2011), pp. 153-160, ISSN 1175-8783, Available from:

http://www.tandfonline.com/doi/abs/10.1080/01140671.2011.559255

Weibel, A., Johnson, R.S. \& DeJong, T.M. (2003). Comparative vegetative growth responses of two peach cultivars grown on size-controlling versus standard rootstocks. Journal of the American Society for Horticultural Science, Vol.128, No.4, (April, 2003), pp. 463-471, ISSN 0003-1062 


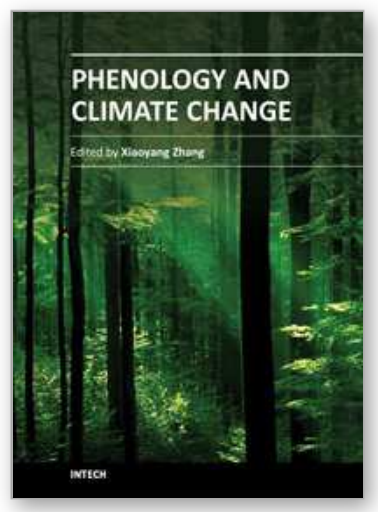

\author{
Phenology and Climate Change \\ Edited by Dr. Xiaoyang Zhang
}

ISBN 978-953-51-0336-3

Hard cover, 320 pages

Publisher InTech

Published online 21, March, 2012

Published in print edition March, 2012

Phenology, a study of animal and plant life cycle, is one of the most obvious and direct phenomena on our planet. The timing of phenological events provides vital information for climate change investigation, natural resource management, carbon sequence analysis, and crop and forest growth monitoring. This book summarizes recent progresses in the understanding of seasonal variation in animals and plants and its correlations to climate variables. With the contributions of phenological scientists worldwide, this book is subdivided into sixteen chapters and sorted in four parts: animal life cycle, plant seasonality, phenology in fruit plants, and remote sensing phenology. The chapters of this book offer a broad overview of phenology observations and climate impacts. Hopefully this book will stimulate further developments in relation to phenology monitoring, modeling and predicting.

\title{
How to reference
}

In order to correctly reference this scholarly work, feel free to copy and paste the following:

Norberto Gariglio, Marcela Weber, Damián Castro and Norma Micheloud (2012). Influence of the Environmental Conditions, the Variety, and Different Cultural Practices on the Phenology of Peach in the Central Area of Santa Fe (Argentina), Phenology and Climate Change, Dr. Xiaoyang Zhang (Ed.), ISBN: 978953-51-0336-3, InTech, Available from: http://www.intechopen.com/books/phenology-and-climatechange/influence-of-the-environmental-conditions-the-variety-and-different-cultural-practices-on-the-phenol

\section{INTECH}

open science | open minds

\section{InTech Europe}

University Campus STeP Ri

Slavka Krautzeka 83/A

51000 Rijeka, Croatia

Phone: +385 (51) 770447

Fax: +385 (51) 686166

www.intechopen.com

\section{InTech China}

Unit 405, Office Block, Hotel Equatorial Shanghai

No.65, Yan An Road (West), Shanghai, 200040, China

中国上海市延安西路65号上海国际贵都大饭店办公楼 405 单元

Phone: +86-21-62489820

Fax: $+86-21-62489821$ 
(C) 2012 The Author(s). Licensee IntechOpen. This is an open access article distributed under the terms of the Creative Commons Attribution 3.0 License, which permits unrestricted use, distribution, and reproduction in any medium, provided the original work is properly cited. 